\title{
A new brittle star from the early Carboniferous of Poland and its implications on Paleozoic modern-type ophiuroid systematics
}

\author{
Ben Thuy, Manfred Kutscher, and Bartosz J. Płachno \\ Acta Palaeontologica Polonica 60 (4), 2015: $923-929$ doi:http://dx.doi.org/10.4202/app.00093.2014
}

The fossil record of Paleozoic ophiuroids includes a number of forms which share striking similarities with modern relatives in terms of skeletal morphology. These so called modern-type Paleozoic ophiuroids yield an enormous potential for a better understanding of ophiuroid evolution, yet the scarcity of accurate and sufficiently detailed morphological descriptions available to date precludes any further-reaching assessments. Here, we describe an articulated ophiuroid specimen from the Late Tournaisian (early Carboniferous) of Czatkowice quarry, southern Poland, as a new species Aganaster jagiellonicus sp. nov. The good preservation of the specimen allowed for a morphological analysis at a level comparable to recent ophiuroid descriptions. It shows remarkable morphological similarities with extant former ophiolepidids Ophiomusium and Ophiosphalma. The new find thus contributes to a solid basis for future investigations on the position of the modern-type Paleozoic ophiuroid in the phylogeny of the class.

Key words: Echinodermata, Ophiuroidea, crown-group, evolution, Carboniferous, Tournaisian, Poland.

Ben Thuy [nebyuht@yahoo.com], Natural History Museum Luxembourg, Department of Palaeontology, 24, rue Münster, 2160 Luxembourg; Manfred Kutscher [kutscher@kreidemuseum.de], Dorfstrasse 10, 18546 Sassnitz, Germany; Bartosz J. Płachno [bartosz.plachno@uj.edu.pl], Department of Plant Cytology and Embryology, Jagiellonian University, ul. Gronostajowa 9, 30-387 Cracow, Poland.

This is an open-access article distributed under the terms of the Creative Commons Attribution License (for details please see creativecommons.org), which permits unrestricted use, distribution, and reproduction in any medium, provided the original author and source are credited. 
Fof Full text $(756.1 \mathrm{kB})$ 